\title{
Nonprofit contracting and partnership in elderly care: a comparison between china and the Netherlands
}

\author{
Yijia Jing $^{1} \cdot$ René Torenvlied $^{2}$ (D) Minna van Gerven ${ }^{3} \cdot$ Jia Cao $^{1}$
}

Received: 30 December 2020 / Accepted: 1 February 2021 / Published online: 29 March 2021

(c) The Author(s) 2021

\begin{abstract}
This paper offers an empirical account of the engagement and success of nonprofits in contracting for elderly care in China and the Netherlands as two contrasting contexts. While contracting as an innovation demonstrates a state-centered approach in China, its Dutch counterpart has sought a balance between state and professional influences. The paper argues that public sector reforms, civil society development and social regulation support schemes contextualize the engagement and success of nonprofits in contracting for elderly care. Surveys among the managers of 176 elderly care organizations in Shanghai and 70 elderly care organizations in the Netherlands shows that the fundamental elements of nonprofit contracting in elderly care are strikingly similar between both contexts, although their manifestation is shaped by each specific institutional context.
\end{abstract}

Keywords Nonprofit contracting $\cdot$ Partnership $\cdot$ Elderly care $\cdot$ China $\cdot$ Netherlands

René Torenvlied

r.torenvlied@utwente.nl

Yijia Jing

jingyj@fudan.edu.cn

Minna van Gerven

minna.vangerven@helsinki.fi

Jia Cao

jiacao18@fudan.edu.cn

1 Fudan University, Shanghai, China

2 University of Twente, Enschede, Netherlands

3 University of Helsinki, Helsinki, Finland

记 Springer 


\section{Introduction}

Demographic change is an important challenge for many countries across the globe. Especially an ageing population has become a major concern for governments all over the globe. Given the prevalence of the population of elderly, and limited capacities of the younger generation to provide informal care, governments feel an urgent need for new structures to govern the provision of elderly care. Driven by forces of globalization, New Public Management (NPM) arose as an external pressure for reform. While NPM assumes that market forces will stimulate quality in service delivery and the development of innovations (Hood, 1991), New Public Governance (NPG) approaches stress the importance of collaboration for service delivery and innovation-pooling of resources in trusted and interdependent contexts (Eikenberry \& Kluver, 2004; Osborne, 2006; Knutsen, 2017; Pen \& Liang, 2019). Countries that face a strong pressure on elderly service delivery developed public innovations from a collaborative perspective. A particular public innovation is the development of nonprofit contracting and partnerships between local governments and the providers of elderly care (Brown \& Potoski, 2004; Van Slyke, 2006). Often these partnerships are embedded in larger collaborative networks of government, nonprofits, and private organizations (Eikenberry \& Kluver, 2004; Jing, 2018).

Local nonprofit partnerships in elderly care, however, are embedded in political-administrative, social and cultural contexts that may vary substantially across the globe. Context matters a lot for the success of public innovations. What works (and is appropriate) in one context may not be working in another context (Pawson \& Tilley, 1997). Contexts can be characterized in terms of their political-administrative system, such as: concentration of power, administrative capacity, or level of (de)centralization (Meier, Rutherford \& Avellaneda, 2017; Pollitt \& Bouckaert, 2017). Contexts in the field of social entrepreneurship include characteristics of culture (e.g., religiosity and tradition), socio-economic characteristics, and domain-specific characteristics (Chandra \& Kerlin, 2020).

In the present article, we focus on political-administrative characteristics of the context. Although we know that such characteristics matter for successful public management, our knowledge about the strength and mechanisms of contextual effects is still in its infancy (cf. Meier, Rutherford \& Avellaneda, 2017). There is a clear need for comparative public management research that explores how our explanatory frameworks operate differently in different contexts. Competitive contracting and partnerships between governments and nonprofits have been extensively studied in the field of public management-primarily in US and European contexts. Chandra and Kerlin (2020) contend that the majority of published social entrepreneurship research has a North American or European orientation.

We address these concerns by focusing on local contracting and partnerships in the provision of elderly care in two contexts: China and the Netherlands. By comparing these two systems, we employ a "diverse-case design" (Seawright \& Gerring, 2008). On the one hand, these contexts face similar challenges and have 
come with a similar public innovation. On the other hand, these two contexts vary widely in their political-administrative and socio-cultural characteristics, making them a unique testing ground for exploring commonalities and differences in our causal explanations (Seawright \& Gerring, 2008, p. 300; Choi, Berry \& Ghadimi, 2020).

We had the opportunity to employ a study among elderly care nonprofit managers in the contexts we have access to: China and the Netherlands. Both countries face a similar challenge of ageing society. Both in China and the Netherlands, elderly care is provided in hybrid modes of governance (Wong, 1994; 2008) in which local government contracting is key in establishing collaborative relations. China and the Netherlands introduced public-nonprofit partnerships (PNPs) in the provision of elderly care. The partnerships predominantly operate on the basis of local government contracting, stressing hybridity between a hierarchical and a market approach.

While the challenges and innovations in China and the Netherlands are quite comparable, the contexts differ widely. Contracting as an innovation demonstrates a state-centered approach in China, whereas its Dutch counterpart sought a balance between state and professional influences. In China, the introduction of contracting aimed to stimulate efficiency and quality in the provision of elderly care. Previous government-nonprofit relations were embedded in administrative hierarchies and blamed as causes of nonprofit incapacities. A market-driven contracting approach was expected to provide nonprofit organizations with more autonomy as well as competition pressures, so they would perform better outside the realms of traditional, close-knit trust networks of officials (Jing \& Chen, 2012). In the Netherlands, contracting between local governments and nonprofits established after a vast decentralization effort. Contracting empowered local governments with the authority to pressure nonprofits to deliver more efficient and higher quality services. At the same time, this decentralization was thought to provide Dutch organizations in elderly care with the flexibility to better tailor their services to client demands, contributing to client satisfaction and efficiency.

The present paper aims to study how these two contexts have shaped the drivers, benefits, success-factors, and scope of nonprofit organizations' partnerships with local governments in the provision of elderly care. To compare the partnerships, we depart from a common framework of nonprofit engagement in contracting and partnerships derived from contracting theory (Brown \& Potoski, 2004; Van Slyke, 2006). The main research question of the present article is twofold: (1) what are the perceived drivers, benefits, success-factors, and scope of partnerships in elderly care contracting in China and the Netherlands? (2) If we observe commonalities and differences, how can we explain them from the combination of theoretical insights in local service contracting and idiosyncratic characteristics of the two contexts?

Data for this comparative study are drawn from two surveys that conceptualize and operationalize the theoretical framework. In China, a survey was held among the leaders of nonprofit organizations in the Shanghai Municipality, a province of China. Most of these organizations provide, among others, elderly care $(n=176$ in sample). In the Netherlands a survey was held among the managers of organizations for elderly care ( $n=70$ in sample). The surveys include contextualized questions 
about factors that promote or hinder success in contractual management and partnerships with local government in the provision of services.

\section{Local contracting and partnerships in China and the Netherlands}

In order to understand how the two contexts shape the drivers, benefits, successfactors, and scope of nonprofit organizations' partnerships in China and the Netherlands we first provide a thick description of the two institutional contexts. We structure our description along four characteristics of the institutional context: state intervention in elderly care, public sector reforms, civil society development, and social regulation and support (cf. Eikenberry \& Kluver, 2004).

\section{State intervention in elderly care}

China In the contexts of the rapid population ageing, long-term care of the elderly population has become a pending concern for governments all over the globe. Longterm care practices are often deeply ingrained in old traditions and societal values. A good example of this is the filial piety tradition that views family as the main caretaker for the frail elderly. This century-long tradition is affirmed in the Chinese Constitution, stating that 'Children who have become of age have the duty to support and assist their parents' (Wu, Carter, Goins \& Cheng, 2005, p. 37). Encouraging a strong role of the family is an inherent policy practice in Chinese urban cities. In Shanghai, the most aged society in China, the so called "90-7-3 framework" was proposed in 2007, aiming to divide the elderly into three groups based on their need for care: $90 \%$ of elderly are expected to rely on family care giving, $7 \%$ on community-based services and 3\% on institutional care (Chen \& Han, 2016). Nonetheless, in China the state has been taking more responsibilities for elderly care since the new century, due to various reasons such as the increasing public sector wealth, the pursuit of a "harmonious society", and the unprecedented aging that was partially caused by decadelong one-child policy. Although government's social and public service spending has increased fast in the last two decades, adequate provision of elderly services still faces serious barriers.

Netherlands In contrast to China, both the income protection (basic old age pension) and long-term care of the elderly have been long a responsibility of the Dutch governments. OECD data show that around $20 \%$ of people aged 65 or older were in receipt of either home care (13\%) or residential care services $(7 \%)$, being one of the highest proportions in the OECD countries in 2006 (Da Roit, 2013). Both residential and non-residential care remain to be largely publicly funded in the Netherlands and private financing comprises only a small part of the total expenditure ( $8 \%$ in 2012 , comprising small income-related co-payments, see: Maarse \& Jeurissen, 2016, p. 242). Public financing, predominantly through social insurance contributions and taxes, is commonly combined with service delivery through nonprofit care providers. 


\section{Public sector reforms}

China In the 1980s both China and the Netherlands started to shift to collaborative service delivery, due to the international influence of NPM and domestic service pressures. Government agencies themselves have been downsized during China's marketization reforms, lacking in-house production capacities (Jing, 2008). Meanwhile, the profit-driven market hardly produced affordable services while governmentsponsored public service units and nonprofit organizations were not professional and capable enough to respond to new elderly service demands. In China, cross-sector collaboration was justified by claims of higher service efficiency and quality and pushed forward by government downsizing. Private organizations were first allowed to invest in public utilities and infrastructures through collaborative arrangements, and later to contract with government on services like information system, building maintenance, and logistical management. The Government Procurement Law was enacted in 2002, legitimating the procurement of services. The fast-growing demands on social services forced Chinese governments to move forward to seek new and capable social service partners. Informal social service contracting got widespread in the 1990s, mostly between government agencies and the nonprofit organizations that they supervised. Yet, growing requirements for transparency, competition and accountability in China's public sector have forged a shift toward market-oriented formal and competitive contracting since the late 1990s. Contracting as an innovation not just aimed at expanded and improved services, but also at reformed governmentnonprofit relations that offered nonprofits more autonomy and external opportunities.

Encouraging nonprofit development has gradually become a formal strategy and a national policy for Chinese government to handle its social service capacity deficits. Professional social service organizations are allowed to deliver services to the elderly based on government contracts or by charging user fees. There are two paths for nonprofit development: one is to allow new nonprofit organizations that are driven by new service demands to emerge and grow; another is to reshape existing nonprofit organizations by making them more professional, autonomous and competitive. These pragmatic changes could only occur gradually in China's social governance system with a traditional emphasis on strict social control, through which governments manage key legitimacy and financial resources available to nonprofit organizations and oversee their operation. China's nonprofit organization policy has been moving ahead only slowly under the tensions between its twin goals of nonprofit development and control (Jing, 2015). Both governments and nonprofits have been cautiously exploring new opportunities offered by contracting.

Contracting has got widespread support from nonprofits in China. A survey of Shanghai nonprofits in 2010 (Jing, 2018) shows that $69 \%$ of the 104 responding nonprofits believed that contracting is a better way compared to direct appropriation from government. The present 2016 survey also shows that $96 \%$ of the 176 nonprofits are willing to have more contracts. Increasing government social service expenditures and changing financing mechanisms have imposed serious pressures on nonprofits whose professional development was only nascent. The service market created by government demands has become a major source of professionalization and modernization of nonprofits in China. Currently, nonprofit organizations 
in China have been engaged in the provision of long-term services for the elderly (Van Gerven, 2019b). In the past, the collaborative networks in elderly services were largely informal and heavily reliant on flexible negotiations and trust, blurring the boundaries between governments and nonprofits. These informal networks were seen to lead to various problems, such as decoupling, nepotism, lacking autonomy and motivation (Jing \& Chen, 2012). While competitive contracting is seen as the answer, earlier work on the topic shows this element still to be weak in China (Jing $\&$ Chen, 2012). Other related institutional reforms are needed to make this market approach work.

Netherlands In the context of population ageing and public austerity, Dutch governments in the last decades increased the use of market mechanisms in its long-term care system. Subsequent Dutch welfare reforms demonstrated a change towards individual responsibility and individual choice, indicating a broader shift from a 'welfare state' to a 'welfare or participatory society' (Van Gerven, 2019a). Similar to China, in the Netherlands family and community support have become more prominent in delivering long-term care for the elderly. The long-term care today in the Netherlands is a field of integrated provisions of institutional and home-care services, with a special focus on autonomy and empowerment of users (clients) and providers. Tailormade solutions are provided by local public and social networks.

Contracting in the Netherlands is the logical continuation of care provision in civil society networks-operating in hybrid quasi-markets (Bies, 2010). Although government is the central initiating actor, it is not strongly involved in these partnerships. While performance measures and quality control are inherent part of the public service delivery in the Netherlands, the partnership in elderly care follows a logic that is closer to NPG than to NPM.

\section{Civil society development}

China Civil society development in China and the Netherlands followed different paths, which fundamentally determined the values and qualifications of the nonprofit sector. Civil society, in its modern sense, only began to emerge since China's reform and opening up in the late 1970s. Following the gradual state retreat from omnipotent social control, a corporatist social regime emerged since the 1980s in response to the new demands and conflicts from a more diverse and freer society. Social organizations could be established legally by registering themselves at a civil affairs agency if they can first have a government agency as their business supervisor. While both requirements aimed at control, they did offer a formal channel of social organization development and led to quick growth of the nonprofits, showing a Chinese version of "voluntary revolution". ${ }^{1}$ Still, the sector has been small and weak. In recent years,

\footnotetext{
1 For example, in 2003 there were 266,612 registered social organizations in China, including 141,167 social groups, 124,491 nonprofit enterprises, and 954 foundations. In the end of 2017 , there were 762,000 registered social organizations, including 355,000 social groups, 400,000 nonprofit enterprises, and 6307 foundations.
} 
local governments have made pilot tests to allow nonprofits in areas like social service and welfare to get directly registered without having a supervisory agency.

The state-society relation in China has been changing slowly under a general framework of selective empowerment and control (Jing, 2015) in which contracting appeared and evolved. Nonprofit organizations, while getting more space in organizational development, are also taking new political obligations like party building. Such an institutional structure tends to induce a pragmatic nonprofit entrepreneurship while avoiding rivalry between governments and nonprofits. Contracting is a "managed social innovation" (Jing \& Gong, 2012) adopted by government to shape the nonprofit sector. Besides the pursuit of professional development, contracting nonprofits are aware of political expectations underlying financial transactions.

Netherlands A well-organized civil society has been the main feature of social welfare and care provision in the Netherlands for decades. In the provision of long-term care in the Netherlands well-organized civil society organizations have already, for decades, shared a responsibility for policy making and service delivery with the state. The "societal midfield" - as the civil society in the Dutch context is often referred to-is defined by the intermediary position of organizations between the individual citizen and the state (Dekker, Völker, Lelieveldt \& Torenvlied, 2010; Brandsen \& Pope, 2015). This was rooted in Dutch pillarization: the accommodation of a diversity of nonprofit organizations with specific religious and social backgrounds in specified policy fields (Brandsen \& Pope, 2015).

Reminiscent of the pillarization, civil society has been deeply engaged in the provision of public services and granted quite some professional autonomy to nonprofit organizations. However, concerns about the quality of public service provision, as well as Anglo-Saxon influences on Dutch national policymaking, introduced strong elements of NPM in the operation of civil society. Although civil society organizations gained a larger share of managerial autonomy, they also became subjected to a regime of stronger performance measures, quality control, as well as obligations to collaborate with other organizations (Bies, 2010; Brandsen \& Pope, 2015). Like in China, contracting in the Netherlands is a type of "managed social innovation" that Jing \& Gong (2012) observe. Government bears the main responsibility for the provision of services but has deliberately chosen to empower the nonprofit sector to take up the role of service delivery without strong state intervention. Similar to China also in the Netherlands the pursuit of professional development comes with an awareness by contracting nonprofits of the political expectations that underlying the financial transactions.

\section{Social regulation and support scheme}

China The prior organizational environments of nonprofits significantly influence how they partner with other organizations in service delivery, determining their capacity of contracting. The social regulation and support schemes in China and the Netherlands are different. China's social regulation/support system, embedded in urban grassroots, is characterized by a close coordination between grassroots governments (GGs) and Urban Residents' Committees (URCs) that GGs supervise (Read, 
2000). Nonprofit organizations first emerged to deliver services as a complement to this system in need of extra capacities. As they were usually organizationally affiliated to the local governments of their service areas, it was easy for them to obtain support from the GG-URC network. For nonprofits coming into a new community due to contracting, a major issue is to familiarize themselves with GGs and URCs so their service delivery will get the necessary permits and support. For example, residents may not open their doors to nonprofit workers unless they are accompanied by URC staff.

The regulation-support structure essentially shapes the service networks of Chinese nonprofits. While they may partner with other nonprofits, and even with private organizations, for operational and professional resources they have to work with state and quasi-state organizations to overcome legitimacy and regulatory barriers. Nonprofits may have to sacrifice organizational autonomy in exchange for a closer relation with governments beyond financial concerns. As was mentioned before, these nonprofits improve their brands and reputation by having good working relations with governments. Nonprofit leaders themselves may also be "coopted" by taking membership in representative state institutions like People's Congress.

Netherlands In the Netherlands the most important organizational environment for nonprofits in elderly care has been the social insurance system, which provides a state-guaranteed financial support system for the elderly. The long-term care is provided through an obligatory health care insurance system that covers both costs of institutional care as well as of home care. The indication of care is provided by a regional authority in the form of a central independent agency ("Centrum Indicatiestelling Zorg") that assesses both the need of care as well as the type and volume of the care provided. The elderly receive in-kind care or can opt-out for cash benefits in purchasing services. While market mechanisms prevail for purchased care, in-kind care is organized by 32 regional purchasing agencies ("Zorgkantoren"). Government sets tariffs and price gaps for care, on which nonprofits may compete.

A major overhaul of long-term care as of 2016 manifested in a considerable shift from residential care to non-residential (home) care, which empowered the social responsibilities of society in the provision of elderly care alongside a rigid implementation of austerity measures (Maarse \& Jeurisse, 2016). The introduction of a more hybrid and market-oriented regulatory framework diversified elderly care, adjusted to the specific needs of the elderly. The transaction costs for introducing this system lie within partnerships of health care nonprofits, public and private organizations, and client organizations. The real costs for the elderly themselves lie in a transfer from the state (that used to organize sole in-kind services and residential care) towards diverse nonprofit organizations providing professionalized elderly care, asking value for money, and collaborating with other nonprofits to meet individualized needs and demands in the home environment. This is a major transformation witnessed in the Netherlands. The greater autonomy of nonprofits for elderly care, and their inclusion in broader civil society partnerships, increased the legitimacy of this transformation. External legitimacy, through professionalization and innovation, is essential when moving from a public elderly care (with elderly nonprofits as a terminal station) towards a networked professional support system 
tailored to the needs of individual elderly. The partnership networks we explored are quintessential for making that transformation a success in the future-both in China and the Netherlands.

\section{Framework for nonprofit engagement in contracting and partnerships}

Competitive contracting and partnerships between governments and nonprofits have been extensively studied in the field of public management (cf. Eikenberry \& Kluver, 2004). Models depart from transaction cost theory: when the agency costs of in-house service production exceed the transaction costs of partner search, contracting and monitoring, then it pays off to outsource the service (cf. Brown \& Potoski, 2004). NPM postulates that market competition, as a driving force, combines with government expectations and professional development into more efficient, flexible, and high-quality service provisions. While most scholarly attention is paid to the outsourcing perspective, it remains understudied why nonprofits would participate in partnerships. Below in Fig. 1 we present a framework for nonprofit engagement in contracting and partnerships that sheds more light on this question. The model has four elements: driving forces behind contracting, nonprofits' perceived benefits, determinants of success, and types and scope of local government-nonprofit partnerships.

\section{Driving forces of nonprofit engagement in contracting (first element)}

From the perspective of nonprofit organizations, the shift we observe towards collaborative service delivery, both in China and the Netherlands, is driven by domestic forces behind the logic of NPM-pushing for a legitimate involvement in contracting. The importance of these driving forces may vary between different nonprofits. We distinguish between three driving forces. In the first place, nonprofit organizations will be concerned with government's demands and expectations when contracting out their services (Savas, 2002; Brown \& Potoski, 2004; Van Slyke, 2006). When contracting out is optimal given (high) levels of internal agency costs, contracting will be based on the initiative of government itself. It requires government to adjust the (legal) institutions regulating the provision of elderly care to facilitate contracting out. The adapted institutions incentivize nonprofit providers of elderly care to engage in contracting, optimizing their chances for survival in a changing institutional environment.

In the second place, with the introduction of NPM-driven public sector reforms nonprofit organizations had to strategically turn to the market to obtain critical capital. NPM reforms usually tend to discourage close government-nonprofit ties; partnerships have to be tested and supported through market competition. Stable and direct financial support from government is reduced sharply under NPM reforms, forcing nonprofits to obtain market contracts by demonstrating their competence (Lee \& Liu, 2012). These changing resource-dependences (Knutsen, 2017) stimulate nonprofits to adopt an entrepreneurial, risk-taking approach, which may result in improved service quality and efficiency, but also in more opportunistic behavior. 


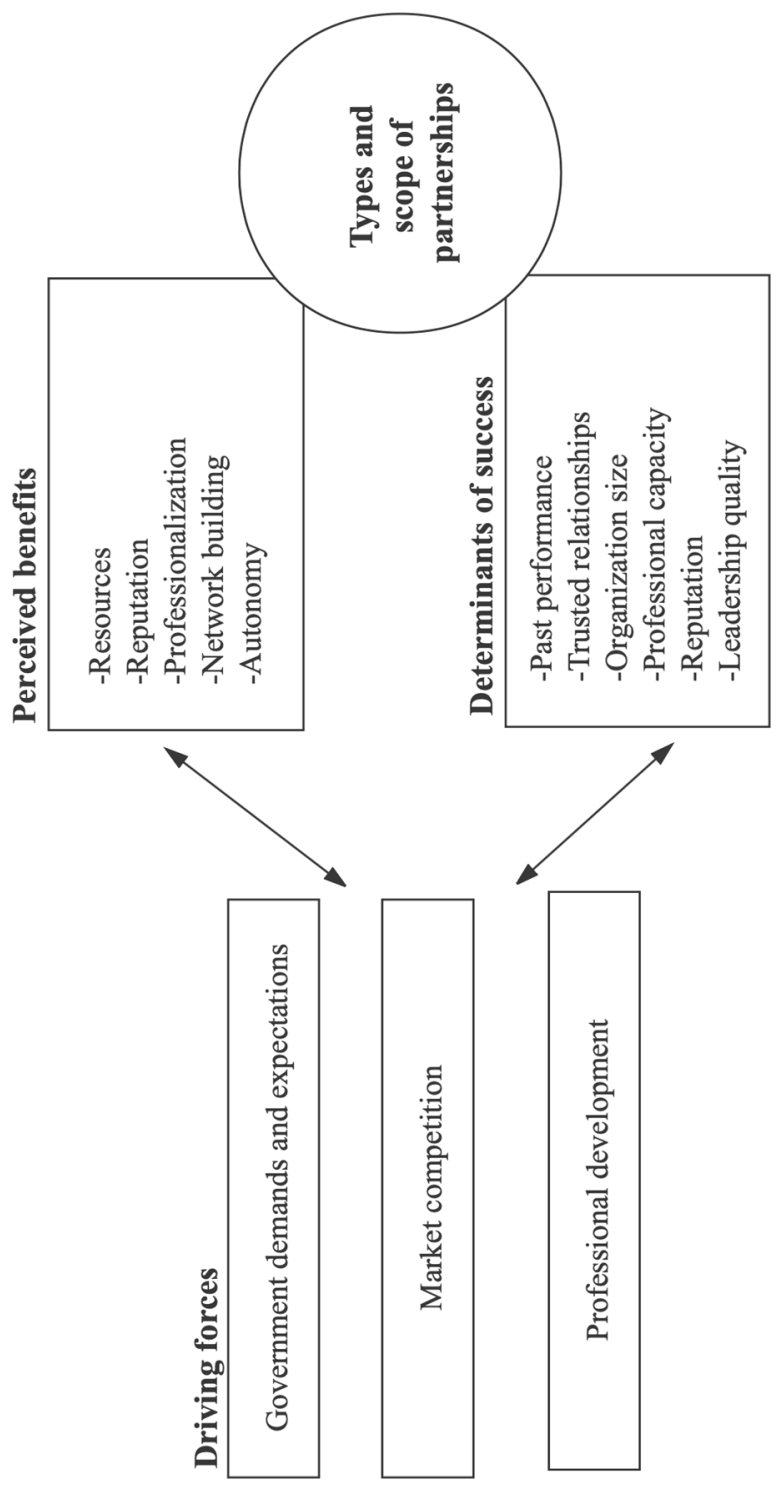

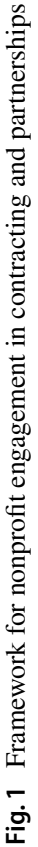


In the third place, nonprofits may engage in contracting out from a need for professional development (Eikenberry \& Kluver, 2004; Van Den Bekerom, Torenvlied \& Akkerman, 2016; Jing, 2018). Formal contracting, as a way to realize public functions through partnerships, usually involves the extension of public rules and norms to new cross-sector partnership networks (Freeman, 2003). For example, the use of public money drives the transparency of, and public accountability for, contracting processes. Consequently, professionalism is both a precondition for, and a result of, contracting. In order to survive, nonprofits must adapt to the (developing) professional norms in the institutional environment of the voluntary sector-providing nonprofits with a partnered opportunity to further professionalize the organization's service provision.

\section{Propositions}

Given the dominance of the NPM framework in both contexts, we expect that organizations for elderly care perceive government demands and expectations to be more important than either of the two other driving forces. Both in China and the Netherlands public/nonprofit contracting in elderly care was introduced by the government to stimulate market conditions for service contracting in this sector. Because of the demographic changes that lie ahead, and a rising self-consciousness of nonprofit communities, we expect professional development to be an important driver as well. We expect that market competition, as the "purest" form of NPM is perceived to be the least important driver of nonprofit engagement in contracting in both contexts. The elderly service market itself is not highly developed in either context, although there is a trend towards personal investments by elderly in the Netherlands.

\section{Perceived benefits of contracting (second element)}

The driving forces of nonprofits' engagement in partnerships are co-determined by the (instrumental) benefits of contracting. Contracting may also bring about various benefits, but also problems to nonprofits that they have to learn to balance (MacManus, 1991). A first benefit is access to resources. Organizations in elderly care must pool resources and organize their resource dependencies in order to provide high-quality care (Knutsen, 2017). The second benefit is the enhancement of the reputation as a high-quality service provider that has been granted a contract (Schalk, Torenvlied \& Allen, 2010). Surviving the procedures and standards for contracting signal a reputation, that is: inclusion in a preferred set of service providers by local government. The third benefit is that contracting provides elderly organizations with the potential to further professionalize their staff, improving conditions for effective internal management of the organization. A fourth benefit is that contracting helps elderly organizations to buffer for instabilities and disruptions in the environment through effective network building (Van Den Bekerom, Torenvlied \& Akkerman, 2016). A final benefit of contracting is more autonomy in service provision, resulting from the shift in hierarchical relations with government to a contractual relationship. 


\section{Propositions}

In both contexts, we expect access to resources to be a major perceived benefit. Due to the shift towards a market-based financing scheme, contracting became the mainstream source of financial revenues for nonprofits. Providers of elderly care in both contexts must learn how to obtain (and maintain) contracts in order to stabilize their revenues. Other benefits may be perceived to be important in varying degree. For example, whereas financial diversification may bring about more autonomy for Dutch nonprofits, non-financial control from Chinese government may make autonomy less visible in that context.

\section{Determinants of contracting success (third element)}

The driving forces of nonprofits engagement in partnerships also co-determine how nonprofits successfully obtain contracts from government. These factors are associated with the "ally principle" from a principal-agent theory, or the concept of "goal alignment" from stewardship theory (Van Slyke, 2006). Various factors may affect the legitimacy of the organization, such as its history and experience (past performance) or prior trusted relationships with local governments and officials. Size of the organization signals a capacity to provide large-scale elderly care. Professional capacity signals the ability to provide high-quality elderly care. Other determinants are the (in)formal reputation in the domain and quality of organizational leadership.

\section{Propositions}

While all these determinants may influence the chance of nonprofits to obtain contracts, we expect that in China prior history of service delivery and prior government-nonprofit ties and trust are especially important. Service contracting in China is still in an early stage and the market is segmented with only few nonprofits available for competition (Jing \& Chen, 2012). Prior service activities and relations, therefore, serve as proxies for professional capacity and political trustfulness. By contrast, for Dutch elderly care we expect that professionalism is a strong determinant for success because of the stepwise introduction of contracting. Thus, in the Netherlands the established reputation of nonprofit organizations will be more important than prior trusted relationships. Information about past performance reduces uncertainty in contracting and, hence, transaction costs. In the more market-oriented context of Dutch elderly care provision political trustfulness is expected to be much less important.

\section{Scope of partnerships (fourth element)}

The driving forces, perceived benefits and determinants of success affect the scope of the partnerships. What types of other organizations collaborate in the partnerships: governments, public service providers, private organizations, political 
organizations, or other nonprofit organizations? Scope of the partnerships is associated with ambitions and complexity (Akkerman \& Torenvlied, 2011; Graddy \& Chen, 2006).

\section{Propositions}

We expect substantial differences between China and the Netherlands as social service networks in the two contexts may have very different starting points and evolutionary paths. Chinese nonprofits have had a history of heavily relying on governmental agencies and semi-official community organizations in service delivery. Recent practices of contracting and upgraded service delivery have invited or pushed them to expand their service networks to include more diverse types of organizations for professional and operational resources. By contrast, Dutch nonprofits have had a long history of nonprofit cooperation on a voluntary basis. Therefore, public organizations may play a role in their networks that may be far less critical than that in China's context. Through its emphasis on cooperation in civil society over the years, Dutch elderly care organizations are expected to have more inclusive and broader networks of collaboration than their Chinese counterparts.

\section{Design and method}

To explore whether our propositions about contracting and local partnerships hold, we surveyed how elderly care organizations in China and in the Netherlands perceive themselves in their contracting practices. We sent surveys to managers of elderly care organizations in both contexts. We decided to choose the Shanghai municipality and the Netherlands as a country as our frameworks for sampling. We did so for two reasons. In the first place, both contexts are roughly comparable in population size. Shanghai has a population of 24.1 million in 2015, about seven million more than the Dutch population. Although Shanghai is not representative of China, its social practices, including nonprofit development such as nonprofit contracting, have long been best practices that inspired other Chinese cities. Consequently, we believe that a comparison of samples of organizations from Shanghai and the Netherlands is illuminating and can inform further studies. In the second place, we had access to survey elderly organizations in these contexts. The questions included in our surveys aimed to tap the importance assigned by these managers to the four elements of our framework model. We slightly adapted constructs in the surveys to accommodate to cultural and institutional characteristics of each context.

\section{Data collection in the Shanghai Municipality}

In June 2016, the Shanghai Community Service Center was invited to distribute questionnaires to a total of 300 social organizations located in all the 16 districts in Shanghai. This service center is a quasi-government agency supervised by the Bureau of Civil Affairs of Shanghai Municipality and a major provider of social service contracts in Shanghai. From the social organizations targeted, 250 nonprofit 
leaders responded. Among them, 176 organizations provided elderly care service. These organizations are included in the analysis for the present study. Among the 176 social organizations that provide elderly care, $83 \%$ are nonprofit enterprises; $15.9 \%$ are social groups; and $1.1 \%$ are foundations. The average organizational size was 15 full-time staff, and average age was 6 years in 2016. Roughly $95 \%$ of them ever gained contracts from government in the past two years, and roughly $90 \%$ gained contracts through a competitive process.

\section{Data collection in the Netherlands}

Data collection in the Netherlands took place in October 2018. The questionnaire was designed to include relevant questions in the Shanghai survey, but there were also questions that reflected the contextual differences in the Netherlands. We sent an online questionnaire to 394 elderly care organizations. These organizations were approached in consultation with the confederation of Dutch elderly care organizations (ActiZ), which has a very high membership rate. In an e-mail to the members we referred to a Qualtrics link and invited managers of these elderly care organizations to participate in the survey. Managerial characteristics reveal that $61 \%$ of the 70 organizations that responded have female heads; average experience in elderly care was 19 years; average organizational size was 105 in terms of employees and 635 in terms of clients. Most elderly care organizations within the sample offer nursing home care $(92 \%)$, institutional nursing care $(87 \%)$ and home care $(79 \%)$.

The online questionnaire was available from the beginning of October until the end of November 2018. The questionnaire took approximately 15 to $20 \mathrm{~min}$ to complete. The first invitation to fill in the questionnaire resulted in 30 respondents who finalized the questionnaire. After sending a reminder, the total number of respondents increased to 70. For some questions, missing values slightly drop the number of cases to a minimum of 61 . The reason for the generally moderate response was probably a concurrent survey, sent by ActiZ to its members-of which we became aware later in the process.

\section{Results}

\section{Driving forces behind nonprofit contracting (first element)}

The importance of driving forces behind nonprofit contracting were measured by asking respondents to indicate the relative importance they attach to various items that tap professional development, government expectations and market competition. In the China survey nonprofit leaders were asked to evaluate general influences from "professional development", "government expectations" and "market competition". In the Dutch survey the drivers "professional development" and "government expectations" were broken down into several items. Importance varies between " 1 " (completely unimportant) to "10" (extremely important).

Table 1 shows a similarity in importance assigned by managers of elderly organizations in both contexts to the drivers, which is in line with our propositions. In 
Table 1 Driving forces of engagement in contracting

\begin{tabular}{lll}
\hline Shanghai elderly care organizations & Mean & SD \\
\hline Professional development $(N=174)$ & 9.07 & 1.28 \\
Government demands and expectations $(N=175)$ & 8.77 & 1.48 \\
Market competition $(N=173)$ & 8.57 & 1.95 \\
\hline Dutch elderly care organizations $(N=61)$ & Mean & SD \\
\hline Professional development & $\mathbf{5 . 9 2}$ & 1.32 \\
Quality improvement in service delivery & 7.57 & 1.85 \\
Labor productivity improvement & 5.39 & 2.69 \\
Cost reductions in service delivery & 4.80 & 2.03 \\
Government demands and expectations & 4.58 & 0.91 \\
New services for current clients & 5.44 & 2.62 \\
New services for new clients & 5.21 & 2.46 \\
Existing services for current clients & 5.03 & 2.10 \\
Pressure from regulations & 3.74 & 2.39 \\
Pressure from local governments and insurers & 3.49 & 2.37 \\
Market competition & 4.31 & 2.45 \\
Increase competitiveness & 4.31 & 2.45 \\
\hline
\end{tabular}

both contexts, the managers of nonprofits in elderly care rank professional development as the most important driver of contracting, followed by government demands and expectations and then market competition. Responses in both contexts show that nonprofits are more sensitive to the government nudge-as a driver of contracting in elderly care- than to market competition. This finding reminds us that contracting in fact happens in a quasi-market environment, embedded in thick public institutions, despite the NPM argumentation supporting the reforms. When contracting, nonprofits have to be sophisticated in handling incentives and constraints set by the government and less driven by the market rationality of business operations. The quasi-market characteristics of elderly care provision in both contexts clearly require sophistication in handling relations with government, whereas market competition serves only as a partial legitimization.

\section{Benefits of contracting (second element)}

The second element in our framework, perceived benefits of contracting, were measured by asking respondents to indicate the relative importance they attach to specific benefits that contracting may have form them as put forward in our framework. Given the different institutional set-up in each context, we slightly adjusted these items in each questionnaire. Importance varies between " 1 " (completely unimportant) to " 10 " (extremely important). Table 2 summarizes the responses.

A comparison of the relative importance of perceived benefits attached by respondents in the two contexts shows that, as expected in our proposition, access 
Table 2 Benefits of contracting for elderly care organizations

\begin{tabular}{llr}
\hline Shanghai elderly care organizations $(N=176)$ & Mean & SD \\
\hline Access to resources & 8.84 & 1.74 \\
Improve professional service ability & 8.84 & 1.58 \\
Strengthen reputation of organization & 8.84 & 1.55 \\
Build a better network with government agencies & 8.63 & 1.74 \\
Complete the tasks from supervisory governments & 8.51 & 1.95 \\
\hline Dutch elderly care organizations $(N=66)$ & Mean & SD \\
\hline Access to resources & 5.36 & 2.84 \\
Improve professional service ability & 5.36 & 2.45 \\
Strengthen collaboration & 5.18 & 2.46 \\
Increase autonomy & 4.77 & 2.73 \\
Strengthen reputation of organization & 4.51 & 2.54 \\
\hline
\end{tabular}

to resources is the most important benefit of contracting. Table 2 shows that, in both contexts, professionalization is considered by respondents to be the second ranked benefit of contracting. In the ranking of the other items, we observe differences between the contexts. Autonomy is considered to be a relatively unimportant benefit of contracting by managers of Chinese nonprofits in elderly care, but also by Dutch managers. Clear differences between the two contexts also exist. While managers of Chinese nonprofits indicate benefits from reputation gain, this item is of least importance to the managers of Dutch elderly care providers. In China, this reputation may reflect the importance of the government-orientation, attachment to traditional values and the status quo.

\section{Determinants of the success in getting contracts (third element)}

After surveying the drivers and benefits of contracting engagement, we asked the managers of the nonprofit organizations in elderly care what determinants they perceive to be important for obtaining contracts. Contracting usually involves a "make or buy" decision and the government may only contract out when contracting nonprofit outperforms its direct employees. Even if there is only a "buy" option, the government may select the best performer through a competitive bidding process. We asked respondents to evaluate six factors with a scale from 1 (completely unimportant) to 10 (extremely important). Table 3 presents the results.

The results reveal almost identical response patterns for the two contexts. Prior service experiences, strong professional capacities and strong organizational reputation are the three determinants deemed most important for successful contracting in both contexts. Apparently, these factors are believed to be the most efficient and reliable indicators of service competence in both contexts. Although we expected, in our proposition, differences in perceptions between the Dutch (professional capacity most important) and Chinese managers (prior service activities and history most important), actually we observe not many qualitative differences. 
Table 3 Factors determining the success of nonprofits in obtaining contracts

\begin{tabular}{llll}
\hline Shanghai elderly care organizations & $N$ & Mean & SD \\
\hline History and experience of providing similar services & 174 & 9.16 & 1.25 \\
Strong professional capacities & 174 & 9.13 & 1.29 \\
Good social reputation & 175 & 9.06 & 1.58 \\
Prior cooperative and trusting relationships with the service & 175 & 8.80 & 1.79 \\
$\quad$ demanding governments & 174 & 7.45 & 2.15 \\
Large size of the organization & 172 & 6.35 & 2.89 \\
Organizational leadership credibility and network & $N$ & Mean & SD \\
\hline Dutch elderly care organizations & 70 & 7.57 & 2.02 \\
\hline Prior client satisfaction & 70 & 7.34 & 1.68 \\
Strong reputation of the organization & 70 & 7.00 & 1.82 \\
Professional capacity & 70 & 6.73 & 2.28 \\
Prior relationships & 70 & 6.03 & 2.40 \\
Network and credible leadership & 70 & 5.53 & 2.33 \\
Size of the organization & & &
\end{tabular}

Organizational size and leadership capability are both deemed as least important determinants for successful contracting by managers from both contexts. In China's culture of collectivism, the nonprofit leaders may refrain from giving high scores when they evaluated this item during the survey. Prior relationships with government are perceived to be of intermediate importance for managers from both contexts. These results may resonate respondents' evaluation of the first element, ranking drivers of contracting in importance from professional development via government expectation to market competition.

\section{Scope of partnership in the service networks (fourth element)}

The final element in the explanatory framework for nonprofit engagement in contracting and partnerships is the type and scope of the service networks in which the nonprofits for elderly care are involved. These service networks are shaped by the institutional environment that provides legitimacy and resources through contracting in service delivery. We measured the self-reported intensity of cooperation with several types of organizations in the partnership network. For each context, we applied a specific approach when measuring cooperation with other organizations in service delivery. We therefore discuss results separately, starting with the Chinese context in Table 4.

In Shanghai, we asked the managers of nonprofits in elderly care to report the intensity of their cooperation with other organizations in service delivery (with " 1 " representing least intensive cooperation and " 5 " representing most intensive cooperation). We formulated the proposition that public organizations play a strong role in Chinese elderly service networks. The responses by the managers of elderly service organizations reflect this proposition. Table 1 shows a declining intensity from 


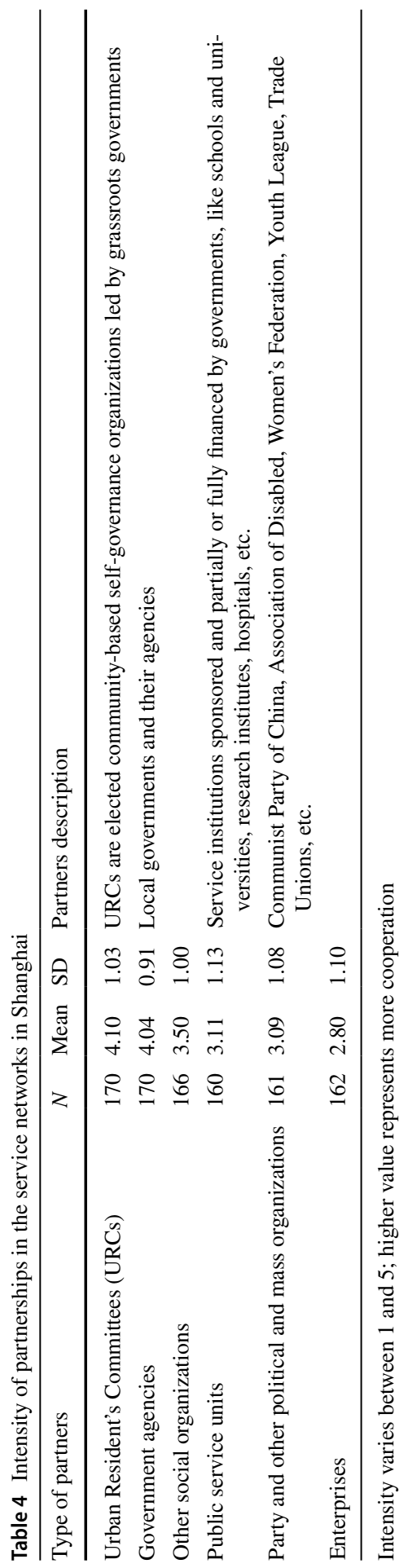


Table 5 Intensity of partnerships in the service networks in the Netherlands $(N=70)$

\begin{tabular}{|c|c|c|c|}
\hline Type of partners & Mean & $\mathrm{SD}$ & Partners description \\
\hline Health care organizations & 0.63 & 0.92 & $\begin{array}{l}\text { Rehabilitation centers, institutions for elderly care, hospitals, } \\
\text { employee organizations in care }\end{array}$ \\
\hline Private organizations & 0.53 & 0.76 & $\begin{array}{l}\text { Advice bureaus, private organizations and business, product } \\
\text { developers }\end{array}$ \\
\hline Public service & 0.20 & 0.60 & Police, schools, knowledge institutions, housing corporations \\
\hline Government & 0.16 & 0.50 & $\begin{array}{l}\text { Municipal government, provincial government, national } \\
\text { government }\end{array}$ \\
\hline Nonprofits & 0.09 & 0.28 & Nonprofit organizations \\
\hline Politicians & 0.04 & 0.20 & Political organizations \\
\hline
\end{tabular}

URCs, local government agencies, other social organizations, public service units, Party and other political and mass organizations, and-lastly-enterprises. This pattern reflects that most social service contracts are community-based in Shanghai and contracting nonprofits must collaborate with urban residence committees, being half-official and half-representational community self-governance organizations (SCNPC, 2018; Mok, 1988; Read, 2000). Urban residence committees offer nonprofits access to local households and provide local information and knowledge. The residence committees help coordinate complex issues and handle local disputes. In addition, contracting nonprofits must work closely with local government agencies in civil affairs, public security, public health, and education-monitoring and regulating service delivery. Other social organizations are sought by contracting nonprofits for resource sharing. Least cooperation exists between nonprofits and enterprises.

In the Netherlands, service network composition was measured by asking the managers of nonprofits in elderly care to indicate the two most important partnership networks they were engaged in. For each partnership network respondents were subsequently asked to tick (from a general list of partnership organizations) whether a specific organization is present in their partnership network (Torenvlied, Akkerman, Meier \& O'Toole, 2013). The general list of partnership organizations comprised health care organizations, private organizations, public service providers, governments, nonprofits, politicians. The responses provide information about the composition of the partnership networks of respondents in terms of the general list of organizations. We pooled organizations over the two partnership networks, providing us with information about the intensity of networking by the nonprofits in elderly care with organizations from the six categories. A value of 0.63 in Table 5 (mean score for health care organizations) reflects that in $63 \%$ of all Dutch nonprofits in elderly care their two most important partnership networks included at least one health care organization.

We formulated the proposition that public organizations are less prominent in the Dutch elderly service networks than in the Chinese. Table 5 shows that results are in line with our proposition. In the Netherlands: health care organizations (albeit nonprofits and hybrid organizations) are the most important network partners for nonprofits in elderly care-while government organizations are much less included 
as a partner. While in China nonprofits is elderly care collaborate least with private organizations, these organizations are second most involved in partnership networks for elderly care in the Netherlands. These results resonate the differences between institutional pathways in the two contexts, with Chinese nonprofits' reliance on governmental agencies and semi-official community organizations and Dutch nonprofits building on a long history of voluntary nonprofit cooperation.

\section{Discussion and conclusion}

In this paper, we offered an empirical account of the engagement and success of nonprofits in contracting for elderly care in China and the Netherlands as two contrasting contexts. We presented a comparative analysis of the institutional contexts that shape nonprofit contracting and partnership. We focused on differences between China and the Netherlands in state intervention in elderly care, public sector reforms, civil society development, and social regulation and support. While contracting as an innovation demonstrates a state-centered approach in China, its Dutch counterpart has sought a balance between state and professional influences. We argued that the paths in institutional development in China and the Netherlands contextualize the engagement and success of nonprofits in contracting for elderly care. To analyze this engagement and success among nonprofit organizations in elderly care, we introduced a general framework that allowed us to empirically capture nonprofit managers in terms of: (1) their perception of the driving forces behind nonprofit contracting in elderly care; (2) their perceived benefits of contracting; (3) their experience about determinants of success, and (4) the structure of their partnership networks.

Our first research question concerned these perceived drivers, benefits, successfactors, and scope of partnerships in elderly care contracting in China and the Netherlands. Both in China and the Netherlands contracting and partnership practices were driven by similar professionalization concerns and less by market pressures, despite the distinct pathways of public sector reform in both contexts. Although contracting itself has all the associations with adopting a market orientation in public service delivery, the survey among the Dutch elderly nonprofits shows that competition is least of their concerns. Similar to their Chinese counterparts, contracting translates, foremost, in further professionalization and modernization. Thus, although both contexts exhibit distinct pathways towards contracting, these pathways have led to strikingly similar practices that are incongruent with the basic tenets of NPM. Both in the Chinese and Dutch context market competition is perceived to be the least important driver by managers of elderly care nonprofits, while these managers have similar concerns with increasing the quality of elderly care under NPG-oriented partnerships.

The NPG orientation to the provision of elderly care in the (institutionally quite different) contexts of China and the Netherlands resonates in other strikingly similar experiences of nonprofit managers from both contexts. In both contexts access to resources and professionalization are reported to be the most important benefits of contracting, rather than increased autonomy (cf. Knutsen, 
2017). Furthermore, prior service experiences, strong professional capacities and organizational reputation are the three determinants deemed most important for successful contracting by nonprofit managers in elderly care from both contexts. Thus, while China and the Netherlands have unique pathways of public sector reforms, civil society development, and social regulation and support-with a distinct socio-economic system and culture-nonprofit contracting and partnership practices, nevertheless, are driven by quite similar forces that result in similar perceived benefits and determinants of success (cf. Eikenberry \& Kluver, 2004; Brown \& Potoski, 2004).

Before we jump, too rapidly, to the conclusion that distinct state-society relations have shaped contracting and partnerships in elderly care (as a public innovation) in a similar way, we do stress that idiosyncratic differences in state-society relations also manifest themselves in nonprofit practices. This addresses our second research question about the influence of idiosyncratic characteristics of the two contexts. The observed differences in practices are shaped by distinct forms of civil society development in China and the Netherlands, as well as institutional differences in social regulation and support between the two contexts. Not surprisingly, we observe those differences primarily in the composition of the partnership networks for elderly care. In China, where state-society relations are hierarchical and transitional, grassroot organizations such as urban residence committees with government agencies and public service units are most important network partners. This is strikingly different in the Netherlands where civil society countered a one-sided market orientation, embedding health care organizations, client groups and private organizations in partnership networks for elderly care.

Our study shows that, while globalization made NPM a common external pressure of reform, public innovations in elderly service delivery to address an ageing population in China and the Netherlands exhibit very similar experiences and practices of NPG. This is an important observation for scholars in comparative public management. Context matters for the specific manifestation of managerial practices of nonprofits (cf. Chandra \& Kerlin, 2020), but the fundamental public management drivers of these practices (Brown \& Potoski, 2004; Eikenberry \& Kluver, 2004; Van Slyke, 2006; Jing, 2018) are strikingly universal across the very different contexts of China and the Netherlands.

Although the self-reported responses are strictly perceptual, our surveys provide a first and important step towards understanding contracting and public-nonprofit partnership practices in different contexts-thus enabling further studies to test hypotheses in more detail. Further research should also include more institutional contexts, especially contexts that adopted a stronger market-driven approach than either China or the Netherlands (cf. Choi, Berry \& Ghadimi, 2020). Further research would also need to include more in-depth studies of practices, aiming to learn from the specific mechanisms that drive best practices in specific contexts. The results of the present study show that we observe similar experiences in quite different contexts. Given the urgent challenge of an ageing population across the globe, this may provide some optimism for global policymakers to learn from best practices in different settings. 
Acknowledgements The authors acknowledge research assistance by Sterre Coenen for data collection in the Netherlands.

\section{Compliance with ethical standards}

Conflict of interest On behalf of all authors, the corresponding author states that there is no conflict of interest.

Open Access This article is licensed under a Creative Commons Attribution 4.0 International License, which permits use, sharing, adaptation, distribution and reproduction in any medium or format, as long as you give appropriate credit to the original author(s) and the source, provide a link to the Creative Commons licence, and indicate if changes were made. The images or other third party material in this article are included in the article's Creative Commons licence, unless indicated otherwise in a credit line to the material. If material is not included in the article's Creative Commons licence and your intended use is not permitted by statutory regulation or exceeds the permitted use, you will need to obtain permission directly from the copyright holder. To view a copy of this licence, visit http://creativecommons.org/licen ses/by/4.0\%.

\section{References}

Akkerman, A., \& Torenvlied, R. (2011). Managing the agency environment: Effects of network ambition on agency performance. Public Management Review, 13(1), 159-174.

Bies, A. L. (2010). Evolution of nonprofit self-Regulation in Europe. Nonprofit and Voluntary Sector Quarterly, 39(6), 1057-1086.

Brandsen, T., \& Pape, U. (2015). The Netherlands: The paradox of government-nonprofit partnerships. VOLUNTAS: International Journal of Voluntary and Nonprofit Organizations, 26(6), 2267-2282.

Brown, T., \& Potoski, M. (2004). Managing the public service market. Public Administration Review, 64(6), 656-668.

Chandra, Y., \& Kerlin, J. A. (2020). Social entrepreneurship in context: Pathways for new contributions in the field. Journal of Asian Public Policy. https://doi.org/10.1080/17516234.2020.1845472.

Chen, L., \& Han, W. J. (2016). Shanghai: front-runner of community-based eldercare in China. Journal of Aging \& Social Policy, 28(4), 292-307.

Choi, D., Berry, F., \& Ghadimi, A. (2020). Policy design and achieving social outcomes: A comparative analysis of social Enterprise policy. Public Administration Review, 80(3), 494-505.

Da Roit, B. (2013). Long-term care reforms in the Netherlands. In C. Ranci \& E. Pavolini (Eds.), Reforms in long-term care policies in Europe (pp. 97-115). New York, NY: Springer.

Dekker, K. K., Völker, B., Lelieveldt, H., \& Torenvlied, R. (2010). Civic engagement in urban neighborhoods: Does the network of civic organizations influence participation in neighborhood projects? Journal of Urban Affairs, 32(5), 609-632.

Eikenberry, A., \& Kluver, J. (2004). The Marketization of the Nonprofit Sector: Civil Society at Risk? Public Administration Review, 64(2), 132-140.

Freeman, J. (2003). Extending public law norms through privatization. Harvard Law Review, 116(5), $1285-1352$.

Graddy, E. A., \& Chen, B. (2006). Influences on the size and scope of networks for social service delivery. Journal of Public Administration Research and Theory, 16(4), 533-552.

Hood, C. (1991). A public management for all seasons? Public administration, 69(1), 3-19.

Jing, Y. (2008). Outsourcing in China: An Exploratory Assessment. Public Administration and Development, 28(2), 119-128.

Jing, Y. (2015). Between control and empowerment: governmental strategies towards the development of the non-profit sector in China. Asian Studies Review, 39(4), 589-608.

Jing, Y. (2018). Dual identity and social organizations' participation in contracting in Shanghai. Journal of Contemporary China, 27(110), 180-192. 
Jing, Y., \& Chen, B. (2012). Is competitive contracting really competitive? Exploring government-nonprofit collaboration in China. International Public Management Journal, 15(4), 405-428.

Jing, Y., \& Gong, T. (2012). Managed Social Innovation: The Case of Government-Sponsored Venture Philanthropy in Shanghai. Australian Journal of Public Administration, 71(2), 233-245.

Knutsen, W. L. (2017). Retaining the benefits of government-nonprofit contracting relationship: Opposites attract or clash? VOLUNTAS: International Journal of Voluntary and Nonprofit Organizations, 28(4), 1373-1398.

Lee, E., \& Liu, H. (2012). Factors influencing network formation among social service nonprofit organizations in Hong Kong and implications for comparative and China studies. International Public Management Journal, 15(4), 454-478.

Maarse, J., \& Jeurissen, P. (2016). The policy and politics of the 2015 long-term care reform in the Netherlands. Health Policy, 120(3), 241-245.

MacManus, S. (1991). Why businesses are reluctant to sell to governments. Public Administration Review, 51(Jul/Aug91), 328-344.

Meier, K. J., Rutherford, A., \& Avellaneda, C. N. (2017). Comparative public management: Why national, environmental, and organizational context matters. Washington, DC: Georgetown University Press.

Mok, B. (1988). Grassroots organizing in China: the residents' committee as a linking mechanism between the bureaucracy and the community. Community Development Journal, 23(Jul 8), 164-169.

Osborne, S. (2006). The new public governance? Public Management Review, 8(3), 377-388.

Pawson, R., \& Tilley, N. (1997). Realistic evaluation. London, CA: Sage.

Pen, X., \& Liang, C. (2019). Before nonprofit organisations become social enterprises. VOLUNTAS: International Journal of Voluntary and Nonprofit Organizations, 30(3), 460-474.

Pollitt, C., \& Bouckaert, G. (2017). Public management reform: a comparative analysis-into the age of austerity. New York, NY: Oxford University Press.

Read, B. L. (2000). Revitalizing the state's urban “nerve tips.” The China Quarterly, 163, 806-820.

Savas, E. S. (2002). Competition and Choice in New York City Social Services. Public Administration Review, 62(1), 82-91.

Schalk, J., Torenvlied, R., \& Allen, J. (2010). Network embeddedness and organizational performance: The strength of strong ties in Dutch higher education. Journal of Public Administration Research and Theory, 20(3), 629-653.

Seawright, J., \& Gerring, J. (2008). Case selection techniques in case study research: A menu of qualitative and quantitative options. Political Research Quarterly, 61(2), 294-308.

Standing Committee of the National People's Congress of China (SCNPC). (2018). Organic Law of the Urban Residents Committee of the People's Republic of China (2018 Amendment). Retrieved from December 12, 2020, http://www.npc.gov.cn/npc/c30834/201901/d0f093d6b5174681826577edd f5d4bb4.shtml.

Torenvlied, R., Akkerman, A., Meier, K. J., \& O’Toole, L. J. (2013). The multiple dimensions of managerial networking. American Review of Public Administration, 43(3), 251-272.

Van Den Bekerom, P., Torenvlied, R., \& Akkerman, A. (2016). Managing all quarters of the compass? How internally oriented managerial networking moderates the impact of environmental turbulence on organizational performance. American Review of Public Administration, 46(6), 639-659.

Van Gerven, M. (2019a). The Dutch Participatory State: Shift from a welfare state of collective solidarity towards individual responsibility in a participatory society. In S. Blum, J. Kuhlmann, \& K. Schubert (Eds.), Routledge Handbook of European Welfare Systems (2nd ed.). London: Routledge.

Van Gerven, M. (2019b). Narrative stories in Chinese characters: political framing of ageing and the welfare reform in China. Policy and Society, 38(3), 502-518.

Van Slyke, D. M. (2006). Agents or stewards: Using theory to understand the government-nonprofit social service contracting relationship. Journal of Public Administration Research and Theory, 17(2), 157-187.

Wong, L. (1994). Privatization of social welfare in post-Mao China. Asian Survey, 34(4), 307-325.

Wong, L. (2008). The third sector and residential care for the elderly in China's transitional welfare economy. Australian Journal of Public Administration, 67(1), 89-96.

Wu, B., Carter, M. W., Goins, R. T., \& Cheng, C. (2005). Emerging services for community-based longterm care in urban China: A systematic analysis of Shanghai's community-based agencies. Journal of Aging \& Social policy, 17(4), 37-60. 